\title{
Tumor-Related Fatigue - an Underestimated Problem
}

Tumor-related fatigue has considerable impact not only on the quality of life of patients but apparently also on the course of treatment. Nearly all patients receiving either radiotherapy, chemotherapy, or immunotherapy experience fatigue to a certain extent. Numbers are ranging from $60-90 \%$ of all patients under active treatment [1]. Furthermore, fatigue very often is still present to a substantial degree even years after successful therapy [2,3]. Tumor-related fatigue, as defined by Kroenke et al. [4], implies a feeling of tiredness, reduced energy level, reduced muscle strength, and cognitive impairment. It may strongly interfere with several aspects of daily life and may therefore have a substantially negative impact on life in general. This definition reflects the complexity of fatigue and, as it is dated from 1988, it shows that fatigue is an issue the medical society has been dealing with for a long time.

Although the problem 'fatigue' has been acknowledged a long time ago, there is still only little information available on the causes of the cancer fatigue syndrome or factors which contribute to its development. This is why the German Fatigue Society (DFaG) was founded in 2002 in order to promote research on fatigue and to provide information for physicians as well as for patients. Since June 2003, the home page of the $\mathrm{DFaG}$ (www.deutsche-fatigue-gesellschaft.de) serves as a source of information and a communication platform for all persons concerned with fatigue. Since October 2003 ONKOLOGIE is the official organ of the DFaG. Notes and announcements of the society as well as articles on fatigue will be published in this journal. This is another important means to reach physicians confronted with fatigue in their patients.

To be able to help patients suffering from fatigue, the doctor has to know about fatigue and its underlying causes. In general, it seems useful to distinguish between acute therapy-related and chronic fatigue, e.g. in long-term survivors. In both cases the tumor itself as well as the treatment are factors inducing fatigue. Medical research is required particularly for the continuing states of tiredness persisting for years.
Management of fatigue is based on a precise diagnosis in the individual patient. As it is evident that primarily the patient's perspective is the basis for diagnosis it may be difficult to decide if the patient is suffering from cancer-related fatigue or not. For daily routine some useful tools have been developed helping the doctor to categorize the patient's complaints: the NCCN (National Comprehensive Cancer Network) has provided an algorithm helping to assess and manage fatigue and the Fatigue Coalition has developed a list of 11 symptoms, 6 of which have to be observed to diagnose fatigue. However, in order to learn more about fatigue it is important to investigate greater numbers of patients. For this purpose tools are needed which assess fatigue in detail and which are applicable in big trials. To meet the subjective experience of fatigue it is necessary to use self-report measures. Therefore, several questionnaires have been developed showing good psychometric characteristics. These questionnaires, e.g. the functional assessment of cancer therapy fatigue scale (FACT-F) or the multidimensional fatigue inventory (MFI), allow a good evaluation of the existence and the course of tumor-caused fatigue $[5,6]$. And, even more important, many patients can be examined and data sets produced that can be compared to normal population or other patient groups.

Treatment of the cancer fatigue syndrome first of all includes correction of the underlying metabolic disorders. Besides diabetes and disorders of the thyroid, most patients suffer from tumor- or treatment-induced anemia. Other common treatment-related side effects, such as pain, cachexia, and nausea, can contribute to the experience of fatigue. But also psychiatric symptoms like depression, anxiety, and sleep disturbances may provoke or deepen fatigue. Many controlled trials showed the effectiveness of erythropoietin in correcting anemia and improving the patient's situation [7, 8]. Other pharmacological approaches include the application of megesterol acetate, prednisone, or methylphenidate to treat fatigue. In the near future the $\mathrm{DFaG}$ will start to test these treatments in randomized trials.

\begin{tabular}{ll}
\hline KARGER & @ 2003 S. Karger GmbH, Freiburg \\
Fax +497614520714 & Accessible online at: \\
$\begin{array}{l}\text { E-mail Information@Karger.de } \\
\text { www.karger.com }\end{array}$ & www.karger.com/onk
\end{tabular}

Dr. med. Jens Ulrich Rüffer

Deutsche Fatigue Gesellschaft e.V. (DFaG)

Maria-Hilf-Straße 15

D-50677 Köln

Tel. +49 22193 115-96, Fax -97

E-mail rueffer@deutsche-fatigue-gesellschaft.de 
For acute and - even more important - for long-term fatigue physical training and psycho-oncological interventions, like supportive psychotherapy to help patients to cope with the disease, are very effective treatment options. The effectiveness of exercise programs has been shown in several trials. Although these trials comprised only a small group of patients it can be assumed that fatigue will be eased by special exercise programs. To advise these patients to take additional rests is counterproductive in most cases. For the future it will be of great importance to define the optimal treatment program and schedule and to identify those patients profiting most from treatment.
Providing the patient with adequate information about fatigue has been demonstrated to be beneficial for coping. Misunderstandings leading to discomfort and thus enforcing fatigue will be prevented: patients who know they are suffering from fatigue will not search for other explanations, like believing tumor therapy was not effective or the tumor is recurrent. Therefore, providing information for patients is one of the main goals of the DFaG.

J.U. Rüffer, Köln for the DFaG (Deutsche Fatigue Gesellschaft)

\section{References}

1 Cella D, Davis K, Breitbart W, Curt G: Cancer-related fatigue: Prevalence of proposed diagnostic criteria in a United States sample of cancer survivors. J Clin Oncol 2001;19:3385.

2 Bower J, Ganz P, Desmond K: Fatigue in breast cancer survivors: Occurrence, correlates, and impact on quality of life. J Clin Oncol 2000;18:743753.

3 Rüffer JU, Flechtner H, Tralls P, Josting A, Sieber M, Lathan B, Diehl V for the GHSG: Fatigue in long-term survivors of Hodgkin's lymphoma; a report from the German Hodgkin Lymphoma Study Group (GHSG). Eur J Cancer 2003;39:2979-2986.
4 Kroenke K, Wood DR, Mangelsdorff AD, Meier NJ, Powell JB: Chronic fatigue in primary care. Prevalence, patient characteristics, and outcome. JAMA 1988;260:929-934.

5 Cella D: The Functional Assessment of Cancer Therapy-Anemia (FACT-An) Scale: A new tool for the assessment of outcomes in cancer anemia and fatigue. Semin Hematol 1997;34(suppl 2):63-74.

6 Smets EM, Garssen B, Bonke B, De-Haes JC: The Multidimensional Fatigue Inventory (MFI) psychometric qualities of an instrument to assess fatigue. J Psychosom Res 1995;39:315-325.
7 O'Shaughnessy JA: Effects of epoetin alfa on cognitive function, mood, asthenia, and quality of life in women with breast cancer undergoing adjuvant chemotherapy. Clin Breast Cancer 2002;3 (suppl 3):S116-S120.

8 Österborg A, Brandberg Y, Molostova V, Iosava G, Abdulkadyrov K, Hedenus M, Messinger D; Epoetin Beta Hematology Study Group: Randomized, double-blind, placebo-controlled trial of recombinant human erythropoietin, epoetin Beta, in hematologic malignancies. J Clin Oncol 2002;20:24862494. 